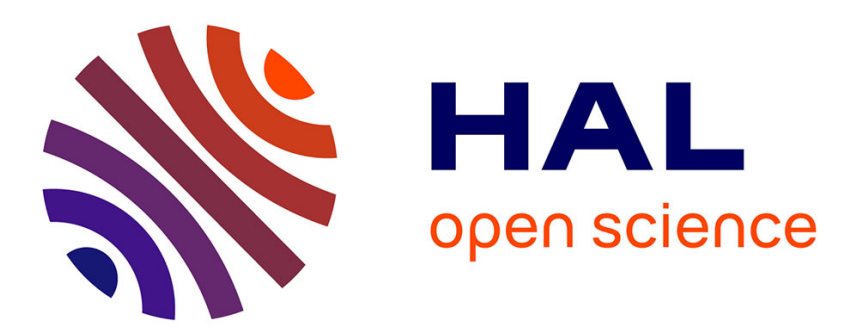

\title{
Discriminating value of HR-pQCT for fractures in women with similar FRAX scores: A substudy of the FRISBEE cohort
}

Sylvie Isabelle Cappelle, Michel Moreaux, R. Karmali, L. Iconaru, F. Baleanu, V. Kinnard, Marianne Paesmans, S. Rozenberg, M. Rubinstein, M. Surquin, et al.

\section{To cite this version:}

Sylvie Isabelle Cappelle, Michel Moreaux, R. Karmali, L. Iconaru, F. Baleanu, et al.. Discriminating value of HR-pQCT for fractures in women with similar FRAX scores: A substudy of the FRISBEE cohort. BONE, 2021, 143, pp.115613. 10.1016/j.bone.2020.115613 . hal-03047095

\section{HAL Id: hal-03047095 \\ https://hal.science/hal-03047095}

Submitted on 16 Dec 2020

HAL is a multi-disciplinary open access archive for the deposit and dissemination of scientific research documents, whether they are published or not. The documents may come from teaching and research institutions in France or abroad, or from public or private research centers.
L'archive ouverte pluridisciplinaire HAL, est destinée au dépôt et à la diffusion de documents scientifiques de niveau recherche, publiés ou non, émanant des établissements d'enseignement et de recherche français ou étrangers, des laboratoires publics ou privés. 
1 Discriminating value of HR-pQCT for fractures in women with similar FRAX scores: a

\section{2 substudy of the FRISBEE cohort}

3

4 Cappelle S.I. ${ }^{1}$, Moreau M. ${ }^{2}$, Karmali R. ${ }^{3}$, Iconaru L. ${ }^{3}$, Baleanu F. ${ }^{3}$, Kinnard V. ${ }^{3}$, Paesmans M. ${ }^{2}$, Rozenberg S. ${ }^{4}$,

5 Rubinstein M. ${ }^{5}$, Surquin M. ${ }^{1}$, Blard P.-H. ${ }^{6}$, Chapurlat R. ${ }^{7}$, Body J.J. ${ }^{3}$, Bergmann P. ${ }^{8}$

61 Department of Geriatrics, CHU Brugmann, Université Libre de Bruxelles (ULB), Brussels, Belgium

72 Data Centre, Bordet Hospital, Université Libre de Bruxelles (ULB), Brussels, Belgium

83 Department of Internal Medicine, CHU Brugmann, Université Libre de Bruxelles (ULB), Brussels, Belgium

94 Department of Obstetrics and gynaecology, Université Libre de Bruxelles (ULB) and Vrije Universiteit (VUB), Brussels, Belgium

105 Department of Nuclear Medicine, Ixelles Hospital, Université Libre de Bruxelles (ULB), Brussels, Belgium

116 CNRS CRPG Research Unit 7358, Vandoeuvre-lès-Nancy, France

127 INSERM Research Unit 1033-Lyos, Hôpital E. Herriot, Lyon, France

138 Department of Nuclear Medicine, CHU-Brugmann, Université Libre de Bruxelles (ULB), Brussels, Belgium

Corresponding author : Cappelle S.I., e-mail: sylvie.cappelle@chu-brugmann.be

Acknowledgements: the study was supported by IRIS-Recherche, CHU Brugmann and the GIPOB. We sincerely thank all 
Highlights

1

28 - 417 women of the FRISBEE cohort, matched for FRAX, were evaluated by HR-pQCT

29 - Some HR-pQCT parameters, mainly at radius, are discriminating for prevalent fractures

30 - HR-pQCT provides valuable information 


\section{Abstract}

Areal bone mineral density (aBMD) has a low sensitivity to identify women at high fracture risk. The FRAX algorithm, by combining several clinical risk factors, might improve fracture prediction compared to aBMD alone. Several micro-architectural and biomechanical parameters which can be measured by high-resolution peripheral quantitative computed tomography (HR-pQCT) are associated with fracture risk. HR-pQCT in combination or not with finite element analysis (FEA) may be used to improve bone strength prediction.

Our aim was to assess whether HR-pQCT measurements (densities, cortical and trabecular microarchitecture, biomechanical proprieties assessed by FEA) had an added value in predicting fractures in a subgroup of women belonging to the Belgian FRISBEE cohort. One hundred nineteen women who sustained a fracture (aged 60 to 85 years) during the initial follow-up of our cohort had a radius and tibia examination by HR-pQCT and were compared with controls matched for their FRAX score at baseline. We found that low distal radius total (OR= $1.41[1.07-1.86]$ per $\mathrm{SD}, \mathrm{p}<0.05)$ and trabecular densities $(\mathrm{OR}=1.45[1.10-1.90], \mathrm{p}<0.01)$, trabecular number $(\mathrm{OR}=$ 1.32 [1.01-1.72], $\mathrm{p}<0.05)$, intra individual distribution of separation $(\mathrm{OR}=0.73[0.54-0.99], \mathrm{p}<0.05)$ as several FEA parameters were significantly associated with fractures. At the distal tibia, impaired cortical density $(\mathrm{OR}=1.32$ [1.03-1.70] per SD, $\mathrm{p}<0.05)$ and thickness $(\mathrm{OR}=1.29$ [1.01-1.63], $\mathrm{p}<0.05)$ and apparent modulus $(\mathrm{OR}=1.30$ [1.011.66], $\mathrm{p}<0.05$ ) were significantly correlated with fractures. A low ultra distal radial aBMD (UDR) measured at the time of HR-pQCT was significantly associated with fractures (OR=1.67 [1.22-2.28], $\mathrm{p}<0.01)$. Women from both groups were followed further after the realisation of the HR-pQCT and 46 new fractures were registered. In this second part of the study, low UDR aBMD (OR=1.66 [1.18-2.35], $\mathrm{p}<0.01)$, total $(\mathrm{OR}=1.48$ [1.08-2.03], $\mathrm{p}<0.05)$, cortical $(\mathrm{OR}=1.40$ [1.04-1.87], $\mathrm{p}<0.05)$ and trabecular $(\mathrm{OR}=1.37$ [1.01-1.85], $\mathrm{p}<0.05)$ densities or apparent modulus $(\mathrm{OR}=1.49$ [1.07-2.05], $\mathrm{p}<0.05)$ at the radius were associated with a significant increase of fracture risk. At the tibia, only the cortical density was significantly associated with the fracture risk (OR=1.34 [1.02-2.76], $\mathrm{p}<0.05)$. These results confirm the interest of HR-pQCT measurements for the evaluation of fracture risk, also in women matched for their baseline FRAX score. They also highlight that UDR aBMD contains pertinent information.

Key words: osteoporosis; fracture prediction; HR-pQCT; FRISBEE; FRAX; UDR aBMD 


\section{Introduction}

63

Osteoporosis (OP) is a condition characterized by loss of bone mass and bone micro-architectural deteriorations leading to an increased bone fragility and occurrence of fractures [1]. The mechanical properties of bone tissue and the osseous resistance depend on bone mass and bone quality - a complex notion which refers to a combination of micro-architecture, accumulated microscopic damage, collagen maturity and biomechanical modifications, the degree of mineralization, mineral crystal size, non-collagenous proteins and bone turnover [2]. Both bone mass and quality deteriorate with ageing. With increasing life expectancy, the growing size of the ageing population raises the burden of osteoporotic fractures (OFs) and makes it necessary to develop costeffective screening techniques to identify individuals at high risk of fracture in order to provide them an early and appropriate treatment.

The operational diagnosis of OP is based on the measurement of areal bone mineral density (aBMD) by dual-energy X-ray absorptiometry (DXA) and defined by a T-score value more than or equal to 2.5 standard deviations (SD) below the young healthy adult mean at lumbar spine, femoral neck or total hip [1]. This classical definition does not allow an optimal risk prediction since more than half of OFs occur in postmenopausal women classified as osteopenic or with normal BMD [3]. The risk ascribable to bone density in subjects with a fragility fracture is lower than 50\% [4]. A better prediction of OFs should also take into account factors reflecting bone architecture and biomechanical alterations. These are in part determined by several clinical risk factors (CRFs), such as age, low BMI, corticosteroid therapy, a prior fragility fracture or a parental hip fracture history, which are associated with fracture risk independently of BMD [5].

These CRFs, alone or in association with BMD, have been combined to construct different models to calculate OFs probabilities at 5 and 10 years [5]. The most widely used is the FRAX score, which is based on a set of ten CRFs with or without BMD measurement and provides a 10 -year probability to sustain a major osteoporotic fracture (MOF: forearm, shoulder, clinical spine or hip fracture) or a hip fracture. This user-friendly online algorithm has largely proven its ability to improve the fracture prediction with regards to BMD alone, resulting in a better selection of patients requiring a treatment on the basis of a threshold fracture risk, for instance a 10 year risk above $20 \%$ for MOFs [7].

Besides, some micro-architectural parameters not included in aBMD measured by DXA could be associated with 
pQCT) has been developed to get insights into bone micro-architecture. It provides a quantitative 3D assessment of the volumetric BMD (vBMD) for the cortical and trabecular compartments. Owing to a high resolution, it allows the evaluation of cortical porosity and indices of trabecular micro-architecture. The data obtained with HR-pQCT also allow a micro-finite element analysis ( $\mu \mathrm{FEA})$ of bone strength [8].

Multiple cross-sectional and several prospective studies have shown an association of some HR-pQCT parameters with the presence of prevalent fractures or the risk of incident fractures in men and women, persisting after adjustment for CRFs or hip aBMD [9-11].

The Fracture RISk Brussels Epidemiological Enquiry (FRISBEE) study is a large population-based cohort study evaluating risk factors for osteoporotic fractures in post-menopausal Belgian women [12]. We used this cohort to evaluate in an ancillary study the impact of HR-pQCT parameters on fracture risk. Bone quality was evaluated by HR-pQCT in a sub-group of FRISBEE volunteers who fractured after inclusion in the study and was compared to that of women with similar FRAX score at baseline but who did not fracture during the same follow-up period. Both groups were then followed for several years to evaluate if HR-pQCT is a useful predictor of OFs, independently of FRAX or aBMD.

\section{Study population and methods}

This study is a case-control study nested in the FRISBEE project that has been described elsewhere [12]. Briefly, 3560 postmenopausal women, aged between 60 and 85 years, living in the Brussels' area were recruited between July 2007 and June 2013. Their CRFs for OP or fracture were recorded at baseline and are reevaluated each year by telephone contact. All women underwent a spine and hip aBMD measurement at inclusion. Fractures occurring during follow-up were registered and systematically validated by radiological documentation.

\subsection{Participants selection}

To ensure a minimum follow-up period of three years, only the first 1740 women included in the FRISBEE cohort before July 2010 were considered in the present study (Fig. 1). In July 2013, 188 of them had sustained at least one fragility fracture (for a total of 225 fractures as some participants presented multiple fractures). Between August 2013 and September 2014, these 188 women were re-invited for a quantitative and 
124

1125

3126

4

$\begin{array}{ll}5 & 127\end{array}$

6

7128

8

$9 \quad 129$

10

qualitative assessment of their bone architecture by HR-pQCT, for a reevaluation of their CRFs and the realization of a second DXA, including a radius aBMD measurement. One hundred and nineteen accepted to participate. Reasons for non-participation of the 69 women with OFs were: refusal to take part at the investigation for medical reasons or age (31), death (10), lost to follow-up (8), recent investigation by their GP, remoteness or missed appointments (20). For each fracture case who accepted to participate, two controls, matched for their baseline FRAX score, were randomly selected among the sub-group of 1740 women who were similarly reevaluated (HR-pQCT, DXA, CRFs). In order to obtain unbiased estimates of relative risk, controls have been selected by incidence density sampling, using the macro developed by Richardson [13]. This method involves matching each fractured woman (case) to a sample of those with similar risk who had not already fractured at the time of case occurrence (selection without replacement). In other words, women with a fracture could be selected as control, as long as they had not fractured. For example, a woman, included in the study in September 2007, who fractured in August 2009 (time to fracture $=2$ years) can be considered as a control for any other participant who fractured less than 2 years after her inclusion in FRISBEE (whatever the date of this inclusion). This was the case of 24 participants. As HR-pQCT measurements were performed in more subjects than were necessary for defining the control group, a total of 417 evaluations were available. All these 417 participants were followed up and fractures that occurred after the HR-pQCT assessment were registered with the endpoint being the first fracture occurring after the HR-pQCT assessment. This design allowed a hindsight of $5.2 \pm 0.9$ yrs between the inclusion and the realization of the HR-pQCT and a follow-up of $3.6 \pm 0.7$ yrs after the HR-pQCT (September 2018 evaluation).

All procedures were approved by the CHU-Brugmann Hospital ethical committee and participant consent was obtained before study initiation (approval number B07720072493).

\subsection{Clinical risk factor data collection - questionnaire and clinical assessments}

At baseline, all women answered a standardized questionnaire that has been previously described [12]. The following clinical and historical data were collected for each subject: age, BMI, age at menopause, selfreported personal history of low-trauma fracture after $50 \mathrm{yrs}$, history of parental hip fracture, corticosteroid use for more than 3 months, current smoking or excessive alcohol intake ( $\geq 3$ units/day) and chronic diseases known to be causes of secondary osteoporosis. Risk factors not considered in the FRAX model were also collected: notably, a history of falls during the last year, a sedentary lifestyle (defined as $<30$ minutes of light activity per day, e.g walking, carrying light loads, bicycling) [12,14], a simple muscle strength evaluation (evaluated by the 
'sit-to-stand test' [15]), the use of sleeping pills (benzodiazepines), proton pump inhibitors, selective serotonin reuptake inhibitors and the socio-economic level. Hormone replacement therapy, calcium and vitamin D supplementation or specific treatments for OP were also registered.

\subsection{FRAX score calculation}

BMD-FRAX score at inclusion was calculated for each participant, using the web application, available at http://www.shef.ac.uk/FRAX/, on the basis of the different CRFs registered at baseline including BMD at the femoral neck. Women with fractures(s) and controls were matched according to their probability of MOFs, with a tolerance of $\pm 1 \%$ for FRAX scores $\leq 20 \%, \pm 3 \%$ above $20 \%$ and up to $+8 \%$ above $30 \%$ (we systematically selected controls with superior FRAX scores in that category). New FRAX scores with BMD were calculated after the second evaluation considering the modifications of the CRFs and the changes in BMD.

\subsection{Fracture ascertainment}

Only the incident fractures that occurred with minimal or no trauma during follow-up were registered. Fingers, toes, skull and face fractures were not considered. In addition to the MOFs considered in the FRAX model (hip, shoulder, vertebra, wrist), ankle, pelvis, sacrum, elbow, humerus, tibia, scapula, femur and radius fractures were also considered as "other major" fractures in the Frisbee study, as they can directly impact subject morbidity or mortality [16]. If a participant sustained more than one fracture during the follow-up, only the first one was taken into account. All fractures were confirmed by radiographs or surgical reports.

\subsection{Bone mineral density and bone micro-architecture measurements}

Lumbar spine (LS), total hip (TH) and femoral neck (FN) areal bone mineral density (aBMD, g/cm²) was measured using dual energy X-ray absorptiometry (Hologic System 4500W) following conventional procedures. Ultra distal radius aBMD (UDR aBMD) was measured once at the time of the HR-pQCT. Volumetric density and bone micro-architecture were assessed by HR-pQCT (XtremeCT I; Scanco Medical AG, 180 enabling a nominal resolution or voxel size of $82 \mu \mathrm{m}$ ) according to the manufacturer's standard in vivo 181 acquisition protocol (effective energy of $60 \mathrm{kVp}$, x-ray tube current of $95 \mathrm{~mA}$ and matrix size of 1536x1536). 182 Non-dominant distal radius and distal tibia were investigated (if a previous distal radius or tibia fracture was reported, the opposite limb was scanned). Region of interest (ROI) at the radius consisted of a 9 mm length of 184 bone located from 9.5 to $18.5 \mathrm{~mm}$ proximal to the midjoint line of the endplate; at the tibia, it was located from 18522.5 to $31.5 \mathrm{~mm}$ proximal to the tibial extremity $[17,18]$. The choice of a fixed offset distance to define the ROI 
rather a relative position scaled to the individual bone length yields $\sim 2 \%$ and $\sim 6 \%$ error measurement for tibia

and radius, respectively [19]. Such uncertainties are significantly lower than the observed inter-individual variability in our cohort. HR- pQCT outcomes included: total, cortical and trabecular volumetric bone density (Tt.vBMD, Ct.vBMD and Tb.vBMD, mgHA/ $\mathrm{cm}^{3}$ ); cortical thickness (Ct.Th, $\mu \mathrm{m}$, direct method [20]) and porosity (Ct.Po, \%); trabecular number (Tb.N, $\left.\mathrm{mm}^{-1}\right)$, thickness (Tb.Th; mm), separation (Tb.Sp; mm) and intra individual distribution of separation (Tb.Sp.SD, mm). HR-pQCT precision errors (expressed as CV) vary from less than $1.5 \%$ for density measurements to $4.5 \%$ for structural parameters [18]. All scans were scored for motion artifact on a scale of 0 (no artifact) to 4 (significant blurring, cortical discontinuities or streaking): grade 4 images were excluded [21].

\subsection{Finite element analysis (FEA)}

FE models were generated using Image Processing Language (IPL) software provided by Scanco Medical. Material properties were chosen isotropic and elastic. Cortical and trabecular bone elements were assigned a Young's modulus of 20 and $17 \mathrm{GPa}$, respectively [22]. We considered the following FEA-derived variables: the percentage of load carried by the trabecular and cortical bone at the distal and proximal surface of the volume of interest (Tb.Dist.Load, Tb.Prox.Load, Ct.Dist.Load and Ct.Prox.Load, \%, respectively), the average and SD values of the Von Mises stresses in the trabecular and cortical bone (Tb.Av.Stress and Ct.Av.Stress; Tb.SD.stress and Ct.SD.stress, MPa, respectively), the stiffness $(\mathrm{kN} / \mathrm{mm})$, the apparent modulus and the estimated failure load $(\mathrm{N})$.

\subsection{Statistical analyses}

Student's t-tests were used to compare densities, microarchitecture, and mechanical parameters of women in the 2 groups. For the nested case control analysis, odds ratio estimates (OR) with their 95\% CI were obtained using conditional logistic regressions which consider subject matching. Because of the method of controls selection (without replacement from all persons at risk at the time of case occurrence), the sample used is representative of the full cohort and OR should be interpreted as hazard ratios (HR) [23]. Univariate and 212 bivariate (adjustment for OP treatment at the time of HR-pQCT) analysis were conducted.

213 For the 417 patients followed up after HRpQCT, relative risk estimates with their 95\% CI were obtained using 214 Cox model, the endpoint being the first fracture occurring after the HR-pQCT assessment. Each parameter was transformed in SD units in order to express outcomes as ORs or HRs per 1 SD diminution. To gain a better understanding of the interrelationship among highly correlated HR-pQCT parameters, we also conducted in both 
parts a principal component analysis (PCA) for the radius and the tibia separately after standardization of the variables. Very simply, PCA transforms the original interrelated variables into a new set of uncorrelated variables called Principal Components (PCs) (e.g. [24]). PCs are linear combinations of the original variables which represent most of the variance of the dataset. Each PC can be interpreted on the basis of the weight of the initial variables. Finally, as these PCs are uncorrelated, they were used in multivariate analysis as predictor of fracture. In the nested case control part, a multivariate conditional logistic analysis was performed using a backward selection model with a p-value cut-off of 0.05. In the second part, we used a Cox model and a backward selection of the PCs with a p-value cut-off of 0.05. All significance probabilities are for two-sided tested and we set the threshold for significance at $\mathrm{p}<0.05$.

\section{Results}

\subsection{Fractures}

\subsubsection{First part (fractures which occurred before HR-pQCT)}

The main sites of the 225 fractures (including multiple fractures) were the wrist $(25.7 \%)$, the spine (16.0\%), the shoulder $(15.1 \%)$, the ankle $(10.7 \%)$ and the hip $(9.0 \%)$. Out of the 188 considered fractures, 127 were defined as MOFs according to the FRAX model, 34 as "other major" fractures and 27 as minor fractures. Out of the 119 fractures of the HR-pQCT group, 71 were defined as MOFs (8 hips, 16 shoulders, 36 wrists, 11 vertebrae), 23 as “other major' fractures and 25 as minor fractures. The mean time to first fracture was $2.7 \pm 1.7$ yrs [5 days - 6.2 yrs]. All fracture types and numbers are summarized in Table 1.

\subsubsection{Second part (fractures which occurred after HR-pQCT)}

Forty six subjects (30 initially control women and 16 already fractured women) fractured after the HR-pQCT evaluation. Thirty nine of these fractures were defined as MOFs (6 hips, 9 shoulders, 10 wrists, 14 vertebrae) according to the FRAX definition and six as "other major" fractures. New incident fractures occurred $2.2 \pm 1.1$ yrs [18 days -4.4 yrs] after the second evaluation date (Table 1 ). 
1249 Thirty radius and eight tibiae scans had to be excluded because of poor quality. The percentage of rejected scans

2 3250

4 5251 6

did not differ significantly between the fracture and control groups.

According to the study design, women with incident fractures after inclusion in FRISBEE did not differ from FRAX-matched controls for the main CRFs included in the FRAX. As expected, FN aBMD was similar in the two groups. On the contrary, ultra distal radial aBMD measured at inclusion in the sub-study was significantly lower in the fractured group (Fx) (Table 2, left part).

As shown in Table 2, there were statistically significant differences between control and fractured women for several micro-architectural parameters. Fracture cases had lower total and trabecular densities $(\mathrm{p}=0.02$ and 0.01 respectively) and higher Tb.Sp SD $(\mathrm{p}=0.05)$ at the radius. At the tibia, women with fractures had lower cortical density, thickness and higher porosity $(\mathrm{p}=0.01,0.01$ and 0.04 , respectively) than controls.

Concerning biomechanical parameters: at the radius, both trabecular and cortical SD stresses were higher $(\mathrm{p}=0.02)$ in Fx vs non-Fx. Cortical SD stresses were also higher at the tibia $(\mathrm{p}<0.01)$. Apparent modulus and estimated failure load were significantly lower at the distal radius $(\mathrm{p}=0.001$ and 0.05$)$ and tibia $(\mathrm{p}<0.01$ and 0.03). Women with fractures had lower stiffness at the tibia $(\mathrm{p}=0.01)$.

263 At the radius, each SD decrease of Tt.vBMD, Tb.vBMD, Tb.N, Tb.Sp.SD, Trab and Cort.SD.Stress, stiffness, 264 app. modulus and failure load values was significantly associated with fractures $(\mathrm{p}<0.05)$. The association

\subsubsection{Second part (fractures which occurred after HR-pQCT)}

Table 3 shows the follow-up results of the 417 women included in this sub-study ( 37 radius and 11 tibiae scans excluded because of poor quality, no difference of percentage of rejected scans between the two groups). No matching for FRAX was realized for this analysis. Women who sustained incident Fx after HR-pQCT had significantly lower density parameters (Tt.vBMD, Tb.vBMD) at the radius ( $\mathrm{p}=0.02$ and 0.04 respectively), while no significant difference was observed in structural parameters at the tibia. Ultra distal radial (UDR) aBMD was also significantly lower in the fractured group $(\mathrm{p}<0.01)$. FEA showed only a significant difference in the radial apparent modulus between Fx and non-Fx women $(\mathrm{p}=0.01)$.

In this second part, a decrease of aBMD, Tt.vBMD, Ct.vBMD, Tb.vBMD or app. modulus at the radius was associated with a significant increase of fracture risk $(\mathrm{p}<0.05)$, even after adjusting for treatment (except for 
Tb.vBMD). At the tibia, Ct.vBMD was the only parameter significantly associated with fracture risk. After adjustment for treatment or FRAX recalculated at inclusion into the sub-study, none of the HR-pQCT parameters were still significantly predictive but UDR aBMD remained significantly associated with fracture risk.

\subsubsection{Principal component analysis}

In the nested case-control study PCA, four principal components explaining at least $10 \%$ of the total variance emerged for the radius and the tibia. Together they explained $91 \%$ and $86 \%$ of the total variability of our whole set of bone characteristics parameters. For the follow-up, we found three (for the radius) and four (for the tibia) principal components explaining at least $10 \%$ of the total variance and explaining $82 \%$ and $86 \%$ of the total variability at the radius and the tibia, respectively. The correlations of each parameter with the PCs are presented in Table 4, where the highest correlations are marked in bold. These correlations indicate the degree and direction of each of the original variables' contribution to each component.

In both PCAs, the composition of the first PC was quite similar at the radius and the tibia, regrouping the total density (and aBMD for the radius) and several qualitative parameters (cortical and trabecular SD stresses, cortical average stress, stiffness, apparent modulus and failure load). Only the first PC of the radius was significantly associated with an increased fracture risk (HR 1.16 [1.04-1.28], p <0.01). This PC explained by itself $\sim 50 \%$ of the total variance for the radius. Again, the tibia was less predictive.

\section{Discussion}

In this Belgian study, we investigated the predictive value of HR-pQCT for osteoporotic fractures. FRISBEE participants who sustained an incident fracture during the first five years of follow-up were compared to women with similar initial FRAX score. To our knowledge, it is the first study where participants were matched for their FRAX score at inclusion. This approach allows to examine whether HR-pQCT adds information to bone fragility with regards to FRAX with BMD. Moreover, in the second part of the study, all participants were monitored during an average follow-up of 3.6 yrs for the occurrence of fragility fractures.

In this cohort, only 35 out of the 188 women who sustained a fracture (19\%) had a 10-year probability of MOF $\geq 20 \%$ at baseline so that more than $80 \%$ of these would not have been taken into account 309 for treatment considering this fixed threshold ( $76 \%$ would not have been treated if BMD alone had been taken 
into account). In countries where the threshold for therapy depends on age, these proportions are likely to vary,

1311 but a majority of patients would still not be treated. Sornay-Rendu and colleagues found in the OFELY study

2

that approximately half of the women who sustained a fragility fracture were not identified as high risk by the FRAX score [25]. The same was true for the Manitoba cohort-based study or the Lausanne University Hospital study, reflecting that FRAX (and the different defined thresholds) is not always an optimal predictive criteria, as it is the case for BMD [26,27]. Additionally, almost $40 \%$ of the women who sustained a fracture $(74 / 188)$ had an estimated fracture probability lower than $10 \%$ (low risk range). These figures and those from other retrospective or prospective cohorts suggest that the FRAX, just as BMD, underestimates the risk of fragility fractures [7]. This observation is partially explained by the fact that the score does not consider some CRFs that might have an impact on fracture risk. History of falls and physical activity for example could be important [28].

Bone strength first depends on bone density: this important factor explains, depending on the studies, between 60 and $80 \%$ of the variability of bone strength. However, the bone quality, a concept that describes aspects of bone composition and structure, also contributes to bone strength. There is thus room for possible improvement of fracture prediction, using additional quantitative parameters reflecting the bone structure and/or strength. Several studies suggest that HR-pQCT might outperform DXA in fracture risk prediction [10].

Our nested case-control analysis showed that several structural and/or biomechanical parameters characterized those who suffered an incident fracture. This highlights the importance of the structural information. Greater impairments of the trabecular parameters (Tb.vBMD, TbN, Tb.Sp.SD) were observed at the radius of the fractured women while only cortical density, porosity and thickness were statistically associated with fractures at the tibia. The small number of hip fractures present in our sample may impact these results. However, such discrepancies according to the site of measurement were previously noted in other cross- sectional studies comparing HR-pQCT parameters in women with and without prevalent fractures [29,30]. It may be explained by the broader cortical thickness of the tibia and by the fact that the tibia, in contrast to the radius, is a weightbearing bone and is hence exposed to other mechanical stimuli that differently impact the architectural parameters. This difference is also observed in FEA results: a majority of the bone resistance parameters were significantly associated with fractures at the radius, while only the apparent modulus differed significantly between the two groups at the tibia.

In the second part of the study, fewer parameters were predictive for fractures. They were mainly density parameters (Tt.vBMD, Ct.vBMD, Tb.vBMD) and app. modulus at the radius and only D.cort at the tibia. 
341 No association remained significant after adjustment for the FRAX score, which was significantly higher in the

1342

2

3343

4

5344

7345

8

9346

10

11

12

13

14

15

16

17350

18

19

20

21

22

23

24

25

26

27355

28

29

30

31

32

33

34

35

36

37360

38

group of patients who sustained a fracture after the HR-pQCT. This can result from the valuable predictive power of the FRAX tool. However this observation could also arise from an insufficient statistical power resulting from a too small number of incident fractures. The 46 fractures observed during the prospective study were indeed far below the total number of events needed considering the ORs of the retrospective part (i.e. 119 to 484 depending on the considered HR-pQCT parameter; http://sample-size.net/sample-size-survival-analysis [31]). Nevertheless, the data of this subsequent analysis confirm our first conclusions, with both trabecular and cortical densities lower at the radius when only the cortical density identifies those who will fracture at the tibia, and the HRs of the follow up analysis are significantly correlated with the ORs of the nested case study (data not shown). Moreover, the hazard ratios observed in our study are concordant with those of the large international cohort recently described by Samelson et al, where the risk was increased by around 10 to $60 \%$ for 1 SD decrease for each considered parameter [11] (Fig. 2). In that study, HRs were still significant after adjustment for the FRAX.

We did not find any association of cortical porosity at the radius or the tibia with fractures. The association between this parameter and the occurrence of OFs is indeed quite variable in the literature depending on the method used to define the zone of interest for the evaluation. For example, Kral and colleagues using a new more inclusive algorithm (non-threshold-based software) found a correlation between the cortical porosity and the prevalence of non vertebral fractures, independent of the FRAX score [32]. In contrast and unexpectedly, in the GLOW study, history of fracture was associated with lower cortical porosities [30]. The synthesis of the various prospective studies published by Samelson et al did not show any significant association between cortical porosity and fracture risk [11]. The average great age of our cohort ( 75 yrs at HR-pQCT assessment) could also be an explanation: the fact that the majority of bone loss occurs in the cortical compartment after the age of 65 years could have led to bias toward null differences between our groups of participants [33].

Additionally, our results do not indicate that failure load is an independent predictor for fracture (HR 1.22 [0.941.58]). This is at odds with the BoMIC results [11]. Apart from an insufficient power due to the low rate of fracture events in our cohort, this discrepancy could be explained by different methods for failure load calculation, hampering adequate comparison of our results. In the BoMIC consortium, the used FEA conditions are different from one cohort to another. Authors harmonized the data using a modulus of $6.829 \mathrm{GPa}$ (while we 
372

1373

2

$3 \quad 374$

4

5375

6

7376

8

$\begin{array}{ll}9 & 377\end{array}$

10

BoMIC methodology, this leads to an increase of the Failure Load in our cohort [34] and therefore to a lower

risk. When our results are compared to those of the OFELY and STRAMBO studies (2 cohorts included in the BoMIC), that used the same approach than in Frisbee, the HRs were similar (HR 1.44 [1.21-1.72] and 1.79 [1.44-2.23], respectively $[29,35])$

Furthermore, considering that, for economic reasons, the assessment of the bone structure and/or strength by HR-pQCT will not replace the systematic screening of fracture risk by DXA and/or FRAX in a nearby future, we examined if specific groups could benefit from this method. Considering the subgroup of our HR-pQCT cohort having a FRAX score $<20 \%$ (low and intermediate risk): we found in the second analysis that the trabecular thickness of the radius discriminated participants with incident fractures $(\mathrm{p}=0.05$, data not shown). However, the small number of fractures in this ancillary study precludes drawing definitive conclusions.

Finally, it is of interest that UDR aBMD provides a lot of information. Significant risk gradient was associated with this parameter both in the nested case and follow up part of the study, with a risk increase of almost $66 \%$ per SD decrease. The fact that almost all HR-pQCT ORs were no longer significant after adjustment for UDR aBMD supports this conclusion. This results from the strong correlation between the HR-pQCT parameters and the UDR aBMD. Additionally, UDR aBMD is the only variable that is still significant after adjusting for the FRAX score in the follow-up study, keeping in mind that the statistical power of the prospective part is limited. In their prospective study, Biver et al also demonstrated a very good performance of the UDR aBMD for fracture prediction (HR 1.75) [36]. This good predictive power is probably explained by the fact that UDR aBDM combines both trabecular and cortical bone and is thus a pertinent composite predictor of bone strength.

The strengths of our nested case-control study are that all fragility fractures were prospectively assessed and X-ray verified, all CRFs were collected at baseline and confirmed each year by phone and at the time of HRpQCT measurements. A restriction of this analysis is the short delay between baseline and the second evaluation $(5.2 \pm 0.9 \mathrm{yrs})$, while the FRAX predictions are based on a 10 year risk evaluation. Nevertheless, the design of our study guarantees a similar follow-up duration for the Fx and the non-Fx groups. It is also relevant to note that only $10 \%$ of the controls (30/298) had a subsequent fracture during the second period, so during a total 400 period of $8.8 \pm 1.1 \mathrm{yrs}$. In addition to the small number of fractures, the relatively short follow-up (median 3.6 $401 \mathrm{yrs}$ ) of the prospective part of the study is another weakness because, which can explain that some of the 402 measured parameters were not predictive of fractures. 
1404 interest in some subgroups. It is especially of major interest in the understanding of the biomechanical process of 3405 4 6 fracture as well as the action of anti-osteoporotic treatments. Our results highlight the superiority of the radius measurements in postmenopausal women and confirm the interest of the UDR aBMD that contains major information on fracture risk. As follow-up is ongoing, a further prospective analysis of incident fractures is planned. 
[1] Consensus development conference: Diagnosis, prophylaxis, and treatment of osteoporosis, The American Journal of Medicine. 94 (1993) 646-650. https://doi.org/10.1016/00029343(93)90218-E.

[2] I.R. Reid, Overview of Pathogenesis, in: C.J. Rosen (Ed.), Primer on the Metabolic Bone Diseases and Disorders of Mineral Metabolism, John Wiley \& Sons, Inc., Ames, USA, 2013: pp. 357-360. https://doi.org/10.1002/9781118453926.ch41.

[3] WHO, Assessment of Fracture Risk and Its Application to Screening for Postmenopausal Osteoporosis, in: 1994: pp. 1-129.

[4] J.A. Kanis, on behalf of the World Health Organisation Scientific Group, Assessment of osteoporosis at the primary healthcare level., WHO Collaborating Centre, University of Sheffield, UK., 2008. http://www.shef.ac.uk/FRAX/ pdfs/WHO_Technical_Report.pdf.

[5] J.A. Kanis, Diagnosis of osteoporosis and assessment of fracture risk, The Lancet. 359 (2002) 1929-1936. https://doi.org/10.1016/S0140-6736(02)08761-5.

[6] J.A. Kanis, N.C. Harvey, H. Johansson, A. Odén, E.V. McCloskey, W.D. Leslie, Overview of Fracture Prediction Tools, Journal of Clinical Densitometry. 20 (2017) 444-450. https://doi.org/10.1016/j.jocd.2017.06.013.

[7] X. Jiang, M. Gruner, F. Trémollieres, W. Pluskiewicz, E. Sornay-Rendu, P. Adamczyk, P.F. Schnatz, Diagnostic accuracy of FRAX in predicting the 10-year risk of osteoporotic fractures using the USA treatment thresholds: A systematic review and meta-analysis, Bone. 99 (2017) 20-25. https://doi.org/10.1016/j.bone.2017.02.008.

[8] R. Krug, A.J. Burghardt, S. Majumdar, T.M. Link, High-Resolution Imaging Techniques for the Assessment of Osteoporosis, Radiologic Clinics of North America. 48 (2010) 601-621. https://doi.org/10.1016/j.rcl.2010.02.015.

[9] K.K. Nishiyama, E. Shane, Clinical Imaging of Bone Microarchitecture with HR-pQCT, Curr Osteoporos Rep. 11 (2013) 147-155. https://doi.org/10.1007/s11914-013-0142-7.

[10] N. Mikolajewicz, N. Bishop, A.J. Burghardt, L. Folkestad, A. Hall, K.M. Kozloff, P.T. Lukey, M. Molloy- Bland, S.N. Morin, A.C. Offiah, J. Shapiro, B. Rietbergen, K. Wager, B.M. Willie, S.V. Komarova, F.H. Glorieux, HR- pQCT Measures of Bone Microarchitecture Predict Fracture: Systematic Review and Meta- Analysis, J Bone Miner Res. 35 (2020) 446-459. https://doi.org/10.1002/jbmr.3901.

[11] E.J. Samelson, K.E. Broe, H. Xu, L. Yang, S. Boyd, E. Biver, P. Szulc, J. Adachi, S. Amin, E. Atkinson, C. Berger, L. Burt, R. Chapurlat, T. Chevalley, S. Ferrari, D. Goltzman, D.A. Hanley, M.T. Hannan, S. Khosla, C.-T. Liu, M. Lorentzon, D. Mellstrom, B. Merle, M. Nethander, R. Rizzoli, E. Sornay-Rendu, B. Van Rietbergen, D. Sundh, A.K.O. Wong, C. Ohlsson, S. Demissie, D.P. Kiel, M.L. Bouxsein, Cortical and trabecular bone microarchitecture as an independent predictor of incident fracture risk in older women and men in the Bone Microarchitecture International Consortium (BoMIC): a prospective study, The Lancet Diabetes \& Endocrinology. 7 (2019) 34-43. https://doi.org/10.1016/S2213-8587(18)30308-5.

[12] S.I. Cappelle, I. Ramon, C. Dekelver, S. Rozenberg, F. Baleanu, R. Karmali, M. Rubinstein, M. Tondeur, M. Moreau, M. Paesmans, P. Bergmann, J.-J. Body, Distribution of clinical risk factors for fracture in a Brussels cohort of postmenopausal women: The FRISBEE study and comparison with other major cohort studies, Maturitas. 106 (2017) 1-7. https://doi.org/10.1016/j.maturitas.2017.08.010.

[13] D.B. Richardson, An incidence density sampling program for nested case-control analyses, Occupational and Environmental Medicine. 61 (2004) e59-e59. https://doi.org/10.1136/oem.2004.014472.

[14] A. de Bruin, H.S.J. Picavet, A. Nossikov, eds., Health interview surveys: towards international harmonization of methods and instruments, World Health Organization, Regional Office for Europe, Copenhagen, 1996.

[15] M. Csuka, D.J. McCarty, Simple method for measurement of lower extremity muscle strength, The American Journal of Medicine. 78 (1985) 77-81. https://doi.org/10.1016/00029343(85)90465-6. 
[16] D. Bliuc, D.N. Nguyen, V.E. Milch, T.V. Nguyen, J.A. Eisman, J.R. Center, Mortality Risk Associated With Low-Trauma Osteoporotic Fracture and Subsequent Fracture in Men and Women, Jama-Journal of the American Medical Association. 301 (2009) 513-521. https://doi.org/10.1001/jama.2009.50.

[17] A. Laib, H. Haüselmann, P. Rüegsegger, In vivo high resolution 3D-QCT of the human forearm., Technol Health Care. (1998) 6(5-6):329-37.

[18] S. Boutroy, M.L. Bouxsein, F. Munoz, P.D. Delmas, In Vivo Assessment of Trabecular Bone Microarchitecture by High-Resolution Peripheral Quantitative Computed Tomography, The Journal of Clinical Endocrinology \& Metabolism. 90 (2005) 6508-6515. https://doi.org/10.1210/jc.2005-1258.

[19] S.K. Boyd, Site-Specific Variation of Bone Micro-Architecture in the Distal Radius and Tibia, Journal of Clinical Densitometry. 11 (2008) 424-430. https://doi.org/10.1016/j.jocd.2007.12.013.

[20] A.J. Burghardt, H.R. Buie, A. Laib, S. Majumdar, S.K. Boyd, Reproducibility of direct quantitative measures of cortical bone microarchitecture of the distal radius and tibia by HRpQCT, Bone. 47 (2010) 519-528. https://doi.org/10.1016/j.bone.2010.05.034.

[21] M. Sode, A.J. Burghardt, J.-B. Pialat, T.M. Link, S. Majumdar, Quantitative characterization of subject motion in HR-pQCT images of the distal radius and tibia, Bone. 48 (2011) 1291-1297. https://doi.org/10.1016/j.bone.2011.03.755.

[22] N. Vilayphiou, S. Boutroy, E. Sornay-rendu, B. Van rietbergen, F. Munoz, P.D. Delmas, R. Chapurlat, Finite element analysis performed on radius and tibia HR-pQCT images and fragility fractures at all sites in postmenopausal women, Bone. 46 (2010) 1030-1037. https://doi.org/10.1016/j.bone.2009.12.015.

[23] B. Langholz, Case-Control Studies = Odds Ratios: Blame the Retrospective Model, Epidemiology. 21 (2010) 10-12. https://doi.org/10.1097/EDE.0b013e3181c308f5.

[24] Principle component analysis of multivariate time series, in: Multivariate Time Series Analysis and Applications, John Wiley \& Sons, Ltd, Chichester, UK, 2019: pp. 139-161. https://doi.org/10.1002/9781119502951.ch4.

[25] E. Sornay-Rendu, F. Munoz, P.D. Delmas, R.D. Chapurlat, The FRAX tool in French women: How well does it describe the real incidence of fracture in the OFELY cohort, J Bone Miner Res. 25 (2010) 2101-2107. https://doi.org/10.1002/jbmr.106.

[26] W.D. Leslie, L.M. Lix, H. Johansson, A. Oden, E. McCloskey, J.A. Kanis, Independent Clinical Validation of a Canadian FRAX Tool: Fracture Prediction and Model Calibration, Journal of Bone and Mineral Research. 25 (2010) 2350-2358. https://doi.org/10.1002/jbmr.123.

[27] B. Aubry-Rozier, D. Stoll, M.-A. Krieg, O. Lamy, D. Hans, What was your fracture risk evaluated by FRAX® the day before your osteoporotic fracture?, Clin Rheumatol. 32 (2013) 219-223. https://doi.org/10.1007/s10067-012-2106-1.

[28] E.W. Gregg, M.A. Pereira, C.J. Caspersen, Physical Activity, Falls, and Fractures Among Older Adults: A Review of the Epidemiologic Evidence, Journal of the American Geriatrics Society. 48 (2000) 883-893. https://doi.org/10.1111/j.1532-5415.2000.tb06884.x.

[29] S. Boutroy, S. Khosla, E. Sornay-Rendu, M.B. Zanchetta, D.J. McMahon, C.A. Zhang, R.D. Chapurlat, J. Zanchetta, E.M. Stein, C. Bogado, S. Majumdar, A.J. Burghardt, E. Shane, Microarchitecture and Peripheral BMD are Impaired in Postmenopausal White Women With Fracture Independently of Total Hip $T$-Score: An International Multicenter Study, J Bone Miner Res. 31 (2016) 1158-1166. https://doi.org/10.1002/jbmr.2796.

[30] A.E. Litwic, L.D. Westbury, D.E. Robinson, K.A. Ward, C. Cooper, E.M. Dennison, Bone Phenotype Assessed by HRpQCT and Associations with Fracture Risk in the GLOW Study, Calcif Tissue Int. 102 (2018) 14-22. https://doi.org/10.1007/s00223-017-0325-9.

[31] M. Levine, M.H.H. Ensom, Post Hoc Power Analysis: An Idea Whose Time Has Passed?, Pharmacotherapy: Official Journal of the American College of Clinical Pharmacy. 21 (2001) 405-409. https://doi.org/10.1592/phco.21.5.405.34503.

[32] R. Kral, M. Osima, T.T. Borgen, R. Vestgaard, E. Richardsen, Å. Bjørnerem, Increased cortical porosity and reduced cortical thickness of the proximal femur are associated with nonvertebral fracture independent of Fracture Risk Assessment Tool and Garvan estimates in postmenopausal women, PLoS ONE. 12 (2017) e0185363. https://doi.org/10.1371/journal.pone.0185363. 
522
[33] R.M. Zebaze, A. Ghasem-Zadeh, A. Bohte, S. Iuliano-Burns, M. Mirams, R.I. Price, E.J. Mackie, E. Seeman, Intracortical remodelling and porosity in the distal radius and post-mortem femurs of women: a cross-sectional study, The Lancet. 375 (2010) 1729-1736. https://doi.org/10.1016/S0140-6736(10)60320-0.

[34] D.E. Whittier, S.L. Manske, D.P. Kiel, M. Bouxsein, S.K. Boyd, Harmonizing finite element modelling for non-invasive strength estimation by high-resolution peripheral quantitative computed tomography, Journal of Biomechanics. 80 (2018) 63-71. https://doi.org/10.1016/j.jbiomech.2018.08.030.

[35] P. Szulc, S. Boutroy, R. Chapurlat, Prediction of Fractures in Men Using Bone Microarchitectural Parameters Assessed by High-Resolution Peripheral Quantitative Computed Tomography-The Prospective STRAMBO Study: FRACTURE PREDICTION IN MEN BY BONE MICROARCHITECTURAL MEASURES, J Bone Miner Res. 33 (2018) 1470-1479. https://doi.org/10.1002/jbmr.3451.

[36] E. Biver, C. Durosier-Izart, T. Chevalley, B. van Rietbergen, R. Rizzoli, S. Ferrari, Evaluation of Radius Microstructure and Areal Bone Mineral Density Improves Fracture Prediction in Postmenopausal Women, J Bone Miner Res. 33 (2018) 328-337. https://doi.org/10.1002/jbmr.3299. 
1559

2

3560

4

5561

6

7562

8

9563

10

11564

12

13565

14

15

16

17

18

19

20

21

22

23

24

25

26

27

28

29

30

31

32

33

34567

35

36

37568

38

39

40

41

42570

43

44

45571

46

47572

48

49

$50 \quad 573$

51

52

53

54

55

56

57

$58 \quad 576$

59

60

61

62

63

64

65

574

575

577
Figure 1 - Time line and follow-up of the cohort - Study design

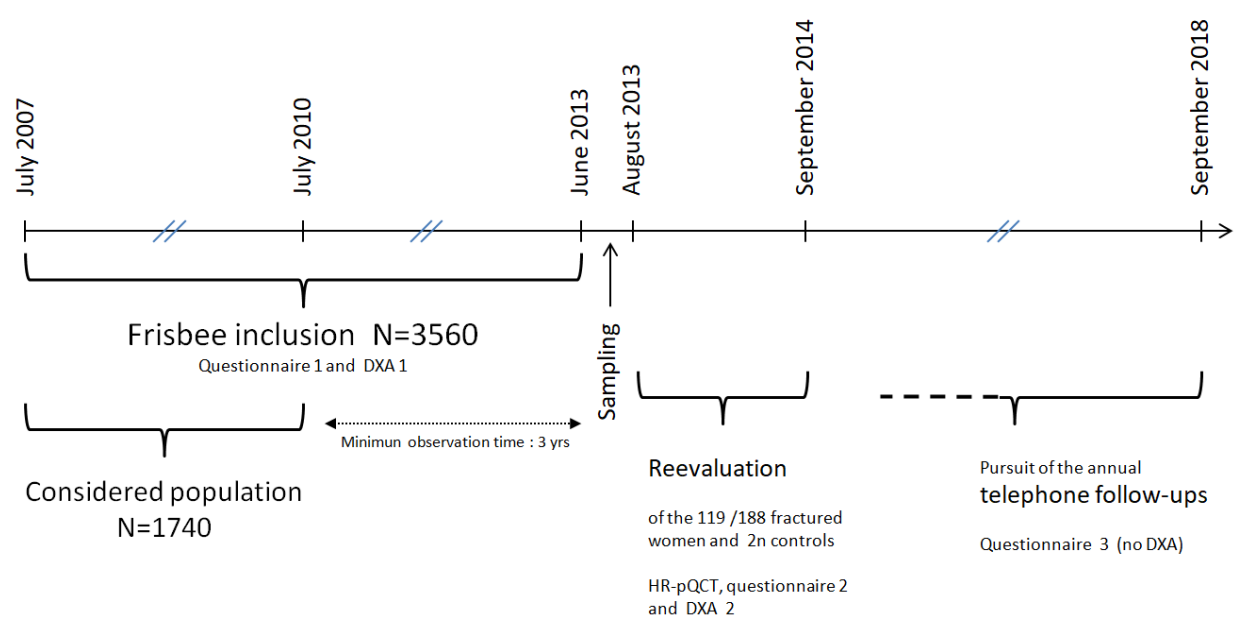


.

2

3

4580

5

7

8

9

10

11583

12584

13585

14586

15587

16

17

18

19

20

21

22

23

24

25

26

27

28

29

30

31

32

33

34

35

36

37

38

39

40

41

42

43

44

45

46

47

48

49

50

51

52

53

54

55

56

57

58

59

60

61

62

63

64

65

588

Figure 2 - Comparison of our results with those of the BoMIC study (data extracted from [11], supplementary

Table 2, women results)

Association between HR-pQCT indices and incidence of fractures. HRs are expressed per SD unit change in bone parameters in the expected direction of increased fracture risk. Shown error bars represent $95 \%$ confidence intervals.

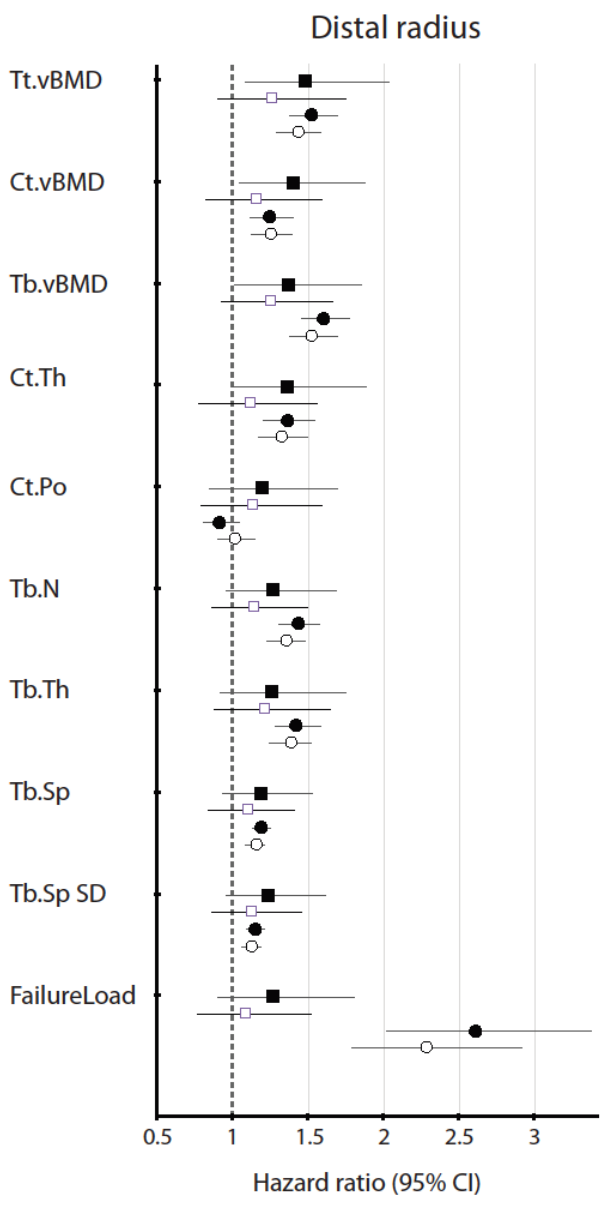

Distal tibia
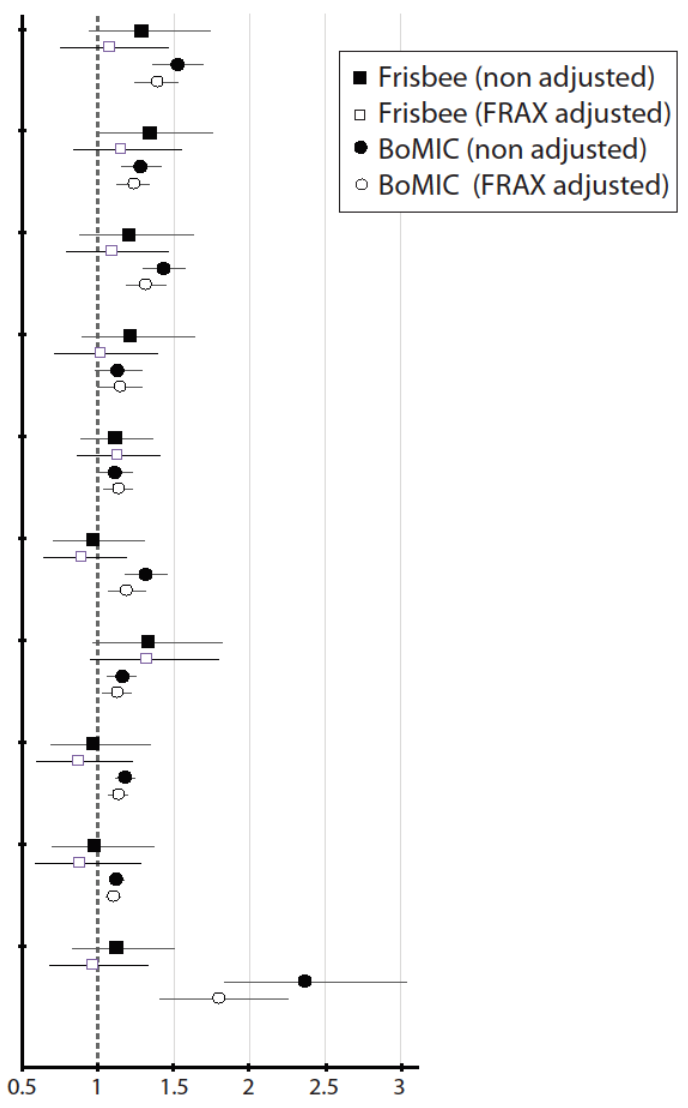

Hazard ratio $(95 \% \mathrm{Cl})$ 
593

594

1595

2596

3

4

5

6

7

8

9

10

11

12

13

14

15

16

17

18

19

20

21

22

23

24

25

26

27

28

29

30

31

32

33

34

35

36

37

38

39

40

41

42

43

44

45

46

47

48

49

50

51

52

53

54

55

56

57

58

59

60

61

62

63

64

65

Table 1: Fractures distribution for Major Osteoporotic Fractures (MOF) according to FRAX and other fractures, mean time to first fracture

\begin{tabular}{|c|c|c|c|c|c|c|c|c|c|}
\hline \multicolumn{2}{|c|}{ Fractures } & \multicolumn{5}{|c|}{ First part - before HR-pQCT } & \multicolumn{3}{|c|}{ Second part - after HR-pQCT } \\
\hline & & $\begin{array}{c}\text { Total } \\
\text { women }\end{array}$ & $\begin{array}{c}\text { With } \\
\text { multiple } \\
\text { fractures }\end{array}$ & $\begin{array}{c}\text { Total } \\
\text { fractures }\end{array}$ & $\begin{array}{c}\text { Reevaluated } \\
\text { women }\end{array}$ & $\begin{array}{c}\text { With } \\
\text { multiple } \\
\text { fractures }\end{array}$ & $\begin{array}{c}\text { Total } \\
\text { women }\end{array}$ & $\begin{array}{c}\text { Initial case } \\
\text { women }\end{array}$ & $\begin{array}{c}\text { Initial control } \\
\text { women }\end{array}$ \\
\hline & Total & 188 & 37 & 225 & 119 & 20 & 46 & 16 & 30 \\
\hline \multirow{4}{*}{ MOFs FRAX } & Hip & 17 & 2 & 19 & 8 & 0 & 6 & 3 & 3 \\
\hline & Shoulder & 29 & 5 & 34 & 16 & 3 & 9 & 3 & 6 \\
\hline & Wrist & 53 & 5 & 58 & 36 & 5 & 10 & 5 & 5 \\
\hline & Vertebrae & 28 & 8 & 36 & 11 & 3 & 14 & 3 & 11 \\
\hline \multirow{7}{*}{$\begin{array}{l}\text { Other major } \\
\text { fractures }\end{array}$} & Pelvis & 7 & 4 & 11 & 5 & 2 & 4 & 1 & 3 \\
\hline & Ankle & 19 & 5 & 24 & 11 & 3 & 1 & 1 & 0 \\
\hline & Elbow & 3 & 1 & 4 & 3 & 1 & 1 & 0 & 1 \\
\hline & Femur & 0 & 1 & 1 & 0 & 0 & 0 & 0 & 0 \\
\hline & Tibia & 1 & 2 & 3 & 1 & 1 & 0 & 0 & 0 \\
\hline & Humerus & 1 & 0 & 1 & 1 & 0 & 0 & 0 & 0 \\
\hline & Sacrum & 3 & 0 & 3 & 2 & 0 & 0 & 0 & 0 \\
\hline \multirow{8}{*}{$\begin{array}{l}\text { Non major } \\
\text { fractures }\end{array}$} & Carpus & 3 & 0 & 3 & 3 & 0 & 0 & 0 & 0 \\
\hline & Clavicle & 1 & 0 & 1 & 1 & 0 & 0 & 0 & 0 \\
\hline & Ribs & 4 & 2 & 6 & 4 & 0 & 0 & 0 & 0 \\
\hline & Metatarsus & 12 & 2 & 14 & 11 & 2 & 0 & 0 & 0 \\
\hline & Metacarpus & 0 & 0 & 0 & 0 & 0 & 1 & 0 & 1 \\
\hline & Patella & 2 & 0 & 2 & 2 & 0 & 0 & 0 & 0 \\
\hline & Scapula & 1 & 0 & 1 & 0 & 0 & 0 & 0 & 0 \\
\hline & Tarsus & 4 & 0 & 4 & 4 & 0 & 0 & 0 & 0 \\
\hline MOFs FRAX & $\%$ & 67.6 & 54.1 & 65.3 & 59.7 & 55.0 & 84.8 & 87.5 & 83.3 \\
\hline All major & $\%$ & 85.6 & 89.2 & 86.2 & 79.0 & 90.0 & 97.8 & 100 & 96.7 \\
\hline $\begin{array}{l}\text { Mean time } \\
\text { to first fracture }\end{array}$ & Days & \begin{tabular}{|l|}
$956 \pm 591$ \\
{$[5-2269]$} \\
\end{tabular} & - & - & $\begin{array}{l}973 \pm 619 \\
{[5-2269]}\end{array}$ & - & $\begin{array}{c}803 \pm 419 \\
{[18-1594]}\end{array}$ & $\begin{array}{c}817 \pm 482 \\
{[18-1594]}\end{array}$ & $\begin{array}{c}795 \pm 391 \\
{[51-1438]}\end{array}$ \\
\hline
\end{tabular}


599 Table 2: HR-pQCT parameters of the women who fractured between inclusion and HR-QCT (Fx) and their

2 matched controls $(\mathrm{C})$ (mean $\pm \mathrm{SD}$, OR [range])

\begin{tabular}{|c|c|c|c|c|c|c|}
\hline & $F x(n=119)$ & $C(n=238)$ & $\mathrm{p}$ & OR per $\downarrow 1$ SD & $\begin{array}{l}\text { OR adjusted for } \\
\text { treatment }\end{array}$ & $\begin{array}{c}\text { OR adjusted for } \\
\text { UDRaBMD }\end{array}$ \\
\hline Initial FRAX & $12,6 \pm 6.7$ & $12,6 \pm 6.7$ & NS & - & - & - \\
\hline Age at baseline (yr) & $70.7 \pm 6.3$ & $69.9 \pm 6.2$ & NS & - & - & - \\
\hline Age at HR-pQCT (yr) & $76.5 \pm 6.3$ & $75.2 \pm 6.1$ & NS & - & - & - \\
\hline FN aBMD at baseline $\left(\mathrm{g} / \mathrm{cm}^{2}\right)$ & $0.703 \pm 0.09$ & $0.693 \pm 0.11$ & NS & - & - & - \\
\hline FN aBMD at HR-pQCT $\left(\mathrm{g} / \mathrm{cm}^{2}\right)$ & $0.668 \pm 0.09$ & $0.667 \pm 0.09$ & NS & $0.98[0.71-1.35]$ & $0.93[0.66-1.30]$ & - \\
\hline OP medication use & $12.6 \%$ & $21.8 \%$ & 0.02 & & & \\
\hline \multicolumn{7}{|l|}{ Radius } \\
\hline$\overline{\mathrm{aBMD}}$ UDR $\mathrm{mg} / \mathrm{cm}^{2}$ & $0.348 \pm 0.07$ & $0.365 \pm 0.06$ & 0.02 & $1.67[1.22-2.28]^{* *}$ & $1.63[1.19-2.23]^{* *}$ & - \\
\hline Tt.vBMD mg/cm ${ }^{3}$ & $263 \pm 58$ & $280 \pm 69$ & 0.02 & $1.41[1.07-1.86]^{*}$ & $1.39[1.05-1.84]^{*}$ & $1.66[0.99-2.80]$ \\
\hline Ct.vBMD mg/cm ${ }^{3}$ & $822 \pm 78$ & $832 \pm 87$ & 0.30 & $1.16[0.89-1.50]$ & $1.15[0.88-1.49]$ & $1.02[0.70-1.49]$ \\
\hline Tb.vBMD mg/cm ${ }^{3}$ & $126 \pm 39$ & $138 \pm 44$ & 0.01 & $1.45[1.10-1.90]^{* *}$ & $1.43[1.08-1.89]^{*}$ & $1.29[0.87-1.92]$ \\
\hline Ct.Th $\mu \mathrm{m}$ & $597 \pm 185$ & $626 \pm 207$ & 0.19 & $1.20[0.92-1.57]$ & $1.18[0.90-1.55]$ & $1.08[0.70-1.68]$ \\
\hline Ct.Po & $69 \pm 6$ & $68 \pm 6$ & 0.13 & $0.83[0.65-1.07]$ & 0.84 [0.65-1.08] & $0.76[0.55-1.05]$ \\
\hline Tb.N* mm-1 & $1.64 \pm 0.42$ & $1.72 \pm 0.39$ & 0.07 & $1.32[1.01-1.72]^{*}$ & $1.29[0.98-1.70]$ & 1.05 [0.74-1.49] \\
\hline Tb.Th $\mu \mathrm{m}$ & $64 \pm 12$ & $66 \pm 13$ & 0.25 & $1.23[0.94-1.62]$ & $1.21[0.92-1.60]$ & $1.28[0.88-1.87]$ \\
\hline Tb.Sp $\mu \mathrm{m}$ & $599 \pm 262$ & $554 \pm 234$ & 0.11 & $0.78[0.59-1.03]$ & $0.78[0.59-1.04]$ & $1.00[0.69-1.44]$ \\
\hline Tb.Sp SD $\mu \mathrm{m}$ & $365 \pm 296$ & $298 \pm 236$ & 0.05 & 0.73 [0.54-0.99]* & $0.74[0.55-0.99]^{*}$ & $0.90[0.62-1.31]$ \\
\hline Trab.Prox.Load \% & $49 \pm 9$ & $50 \pm 10$ & 0.45 & 1.13 [0.87-1.47] & $1.12[0.86-1.46]$ & $1.07[0.78-1.47]$ \\
\hline Trab.Dist.Load \% & $16.7 \pm 8.7$ & $17.5 \pm 8.2$ & 0.39 & 1.18 [0.91-1.53] & $1.17[0.90-1.51]$ & $1.08[0.81-1.46]$ \\
\hline Trab.Av.Stress Mpa & $8.2 \pm 1.7$ & $8.1 \pm 1.7$ & 0.72 & 0.90 [0.69-1.18] & $0.92[0.70-1.20]$ & $1.15[0.80-1.65]$ \\
\hline Trab.SD.Stress Mpa & $5.4 \pm 1.4$ & $5.0 \pm 1.4$ & 0.02 & $0.66[0.49-0.89]^{* *}$ & $0.67[0.50-0.90]^{* *}$ & $0.74[0.47-1.17]$ \\
\hline Cort.Av.Stress Mpa & $16.4 \pm 3.9$ & $15.9 \pm 3.8$ & 0.21 & $0.91[0.83-1.01]$ & $0.92[0.83-1.01]$ & 0.98 [0.83-1.15] \\
\hline Cort.SD.Stress Mpa & $4.3 \pm 1.3$ & $4.0 \pm 1.2$ & 0.02 & $0.67[0.50-0.88]^{* *}$ & $0.68[0.51-0.90]^{* *}$ & $0.67[0.44-1.02]$ \\
\hline Stiffness $\mathrm{kN} / \mathrm{mm}$ & $116 \pm 28$ & $122 \pm 27$ & 0.06 & $1.55[1.12-2.15]^{* *}$ & $1.53[1.10-2.14]^{*}$ & $1.41[0.79-2.51]$ \\
\hline App.Modulus & $2802 \pm 631$ & $3062 \pm 765$ & 0.001 & $1.67[1.24-2.25]^{* * *}$ & $1.65[1.23-2.23]^{* *}$ & $2.41[1.43-4.08]^{* *}$ \\
\hline Est.Failure.Load N & $2774 \pm 665$ & $2919 \pm 634$ & 0.05 & $1.60[1.14-2.23]^{* *}$ & $1.58[1.13-2.21]^{* *}$ & $1.44[0.82-2.25]$ \\
\hline \multicolumn{7}{|l|}{ Tibia } \\
\hline Tt.vBMD mg/cm³ & $227 \pm 50$ & $237 \pm 48$ & 0.07 & $1.21[0.94-1.55]$ & $1.20[0.93-1.54]$ & $1.23[0.85-1.79]$ \\
\hline Ct.vBMD mg/cm ${ }^{3}$ & $761 \pm 86$ & $785 \pm 84$ & 0.01 & $1.32[1.03-1.70]^{*}$ & 1.33 [1.04-1.71]* & $1.28[0.94-1.73]$ \\
\hline Tb.vBMD mg/cm³ & $144 \pm 34$ & $146 \pm 36$ & 0.59 & $1.04[0.82-1.32]$ & $1.01[0.79-1.31]$ & $0.91[0.66-1.26]$ \\
\hline Ct.Th $\mu \mathrm{m}$ & $713 \pm 261$ & $785 \pm 272$ & 0.01 & $1.29[1.01-1.63]^{*}$ & $1.29[1.01-1.64]^{*}$ & $1.30[0.96-1.77]$ \\
\hline Ct.Po & $105 \pm 16$ & $103 \pm 8$ & 0.04 & $0.79[0.62-1.02]$ & $0.79[0.62-1.02]$ & $0.66[0.46-0.95]^{*}$ \\
\hline Tb.N* mm-1 & $1.7 \pm 0.4$ & $1.7 \pm 0.4$ & 0.36 & $0.90[0.72-1.14]$ & $0.88[0.69-1.12]$ & 0.82 [0.61-1.09] \\
\hline Tb.Th $\mu \mathrm{m}$ & $71 \pm 13$ & $74 \pm 15$ & 0.07 & $1.16[0.92-1.46]$ & $1.15[0.91-1.46]$ & $1.09[0.82-1.46]$ \\
\hline Tb.Sp $\mu \mathrm{m}$ & $559 \pm 217$ & $558 \pm 182$ & 0.98 & $0.99[0.78-1.25]$ & $1.01[0.79-1.29]$ & $1.01[0.75-1.34]$ \\
\hline Tb.Sp SD $\mu \mathrm{m}$ & $307 \pm 257$ & $300 \pm 208$ & 0.78 & $0.96[0.77-1.21]$ & $0.98[0.78-1.24]$ & $0.96[0.73-1.28]$ \\
\hline Trab.Prox.Load \% & $57 \pm 9.5$ & $56 \pm 10.2$ & 0.34 & $0.95[0.76-1.18]$ & $0.94[0.75-1.17]$ & $0.87[0.68-1.12]$ \\
\hline Trab.Dist.Load \% & $35 \pm 9.7$ & $34 \pm 10.7$ & 0.53 & $0.91[0.73-1.11]$ & $0.89[0.71-1.12]$ & $0.86[0.66-1.11]$ \\
\hline Trab.Av.Stress Mpa & $4.0 \pm 1.3$ & $3.9 \pm 1.1$ & 0.28 & $0.91[0.73-1.13]$ & $0.92[0.74-1.14]$ & $0.96[0.75-1.23]$ \\
\hline Trab.SD.Stress Mpa & $2.2 \pm 0.8$ & $2.1 \pm 0.7$ & 0.06 & $0.86[0.68-1.08]$ & 0.86 [0.68-1.09] & $0.95[0.72-1.25]$ \\
\hline Cort.Av.Stress Mpa & $7.3 \pm 2.5$ & $6.9 \pm 2.0$ & 0.18 & $0.89[0.72-1.13]$ & $0.91[0.72-1.14]$ & $0.98[0.74-1.28]$ \\
\hline Cort.SD.Stress Mpa & $1.7 \pm 0.7$ & $1.5 \pm 0.5$ & $<0.01$ & $0.79[0.62-1.01]$ & $0.79[0.62-1.01]$ & $0.84[0.63-1.12]$ \\
\hline Stiffness kN/mm & $289 \pm 58$ & $305 \pm 55$ & 0.01 & $1.27[0.98-1.66]$ & $1.26[0.97-1.65]$ & 0.97 [0.68-1.39] \\
\hline
\end{tabular}




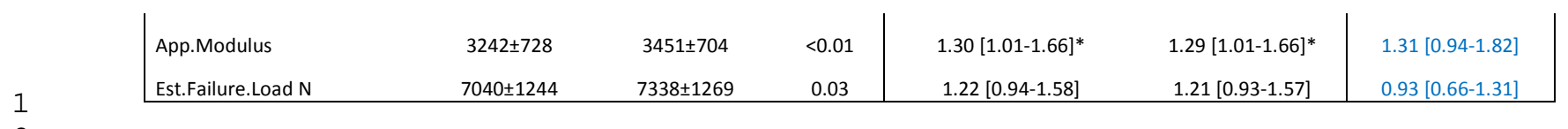

601 Significant levels: * $p<0.05, * * p<0.01, * * * p<0.001$

4

5

8

10

11

12

13

14

15

16

17

18

19

20

21

22

23

24

25

26

27

28

29

30

31

32

33

34

35

36

37

38

39

40

41

42

43

44

45

46

47

48

49

50

51

52

53

54

55

56

57

58

59

60

61

62

63

64

65 
2

\begin{tabular}{|c|c|c|c|c|c|c|}
\hline & $F x(n=46)$ & Non-Fx $(n=371)$ & $\mathrm{p}$ & HR per $\downarrow 1$ SD & $\begin{array}{l}\text { Adjusted for } \\
\text { treatment }\end{array}$ & $\begin{array}{l}\text { Adjusted for } \\
\text { FRAX }\end{array}$ \\
\hline FRAX at baseline & $16.1 \pm 10.2$ & $11.4 \pm 6.4$ & $<0.01$ & - & & \\
\hline FRAX at HR-pQCT & $19.3 \pm 12.2$ & $14.3 \pm 7.1$ & $<0.01$ & - & & \\
\hline Age at HR-pQCT & $76.9 \pm 5.7$ & $74.7 \pm 6.0$ & 0.01 & - & & \\
\hline OP medication use & $30.4 \%$ & $15.6 \%$ & $<0.01$ & - & & \\
\hline $\mathrm{FN}$ aBMD $1\left(\mathrm{~g} / \mathrm{cm}^{2}\right)$ & $0.676 \pm 0.11$ & $0.709 \pm 0.10$ & 0.05 & - & & \\
\hline $\mathrm{FN}$ aBMD $2\left(\mathrm{~g} / \mathrm{cm}^{2}\right)$ & $0.641 \pm 0.09$ & $0.677 \pm 0.09$ & 0.01 & $1.39[0.98-1.98]$ & $1.32[0.92-1.91]$ & $1.13[0.75-1.71]$ \\
\hline \multicolumn{7}{|l|}{$\underline{\text { Radius }}$} \\
\hline aBMD UDR $\mathrm{mg} / \mathrm{cm}^{2}$ & $0.336 \pm 0.07$ & $0.365 \pm 0.06$ & $<0.01$ & $1.66[1.18-2.35]^{* *}$ & $1.63[1.14-2.32]^{* *}$ & $1.47[1.02-2.13]^{*}$ \\
\hline Tt.vBMD mg/cm ${ }^{3}$ & $254 \pm 68$ & $280 \pm 66$ & 0.02 & $1.48[1.08-2.03]^{*}$ & 1.41 [1.02-1.95]* $^{*}$ & $1.25[0.90-1.75]$ \\
\hline Ct.vBMD mg/cm ${ }^{3}$ & $808 \pm 99$ & $836 \pm 78$ & 0.09 & $1.40[1.04-1.87]^{*}$ & $1.35[1.00-1.81]^{*}$ & 1.14 [0.82-1.59] \\
\hline Tb.vBMD mg/cm ${ }^{3}$ & $123 \pm 41$ & $137 \pm 42$ & 0.04 & $1.37[1.01-1.85]^{*}$ & $1.29[0.95-1.76]$ & $1.24[0.92-1.66]$ \\
\hline Ct.Th $\mu \mathrm{m}$ & $574 \pm 212$ & $631 \pm 194$ & 0.08 & 1.36 [0.99-1.88] & $1.30[0.94-1.80]$ & $1.10[0.77-1.56]$ \\
\hline Ct.Po & $70 \pm 7$ & $68 \pm 6$ & 0.06 & 1.19 [0.84-1.69] & $1.16[0.82-1.65]$ & 1.12 [0.79-1.59] \\
\hline Tb.N* mm-1 & $1.6 \pm 0.5$ & $1.7 \pm 0.4$ & 0.14 & $1.27[0.95-1.68]$ & $1.20[0.89-1.61]$ & $1.13[0.86-1.49]$ \\
\hline Tb.Th $\mu \mathrm{m}$ & $63 \pm 13$ & $66 \pm 13$ & 0.12 & $1.26[0.91-1.75]$ & $1.20[0.86-1.67]$ & $1.20[0.87-1.64]$ \\
\hline Tb.Sp $\mu \mathrm{m}$ & $597 \pm 259$ & $554 \pm 223$ & 0.26 & $0.84[0.66-1.08]$ & $0.87[0.67-1.13]$ & $0.92[0.71-1.20]$ \\
\hline Tb.Sp SD $\mu \mathrm{m}$ & $354 \pm 271$ & $304 \pm 245$ & 0.33 & $0.81[0.62-1.05]$ & 0.83 [0.63-1.09] & 0.90 [0.69-1.17] \\
\hline Trab.Dist.Load \% & $49 \pm 9$ & $49 \pm 10$ & 0.74 & $1.18[0.77-1.44]$ & $1.03[0.76-1.39]$ & $1.15[0.85-1.55]$ \\
\hline Trab.Prox.Load \% & $16 \pm 8$ & $17 \pm 8$ & 0.48 & $1.11[0.80-1.53]$ & $1.07[0.78-1.48]$ & 1.18 [0.88-1.59] \\
\hline Trab.Av.Stress Mpa & $8.3 \pm 1.6$ & $8 \pm 1.8$ & 0.45 & $0.89[0.65-1.22]$ & $0.93[0.68-1.27]$ & $1.05[0.78-1.43]$ \\
\hline Trab.SD.Stress Mpa & $5.5 \pm 1.5$ & $5 \pm 1.4$ & 0.05 & $0.77[0.58-1.02]$ & $0.81[0.58-1.016]$ & $0.88[0.67-1.17]$ \\
\hline Cort.Av.Stress Mpa & $17 \pm 4$ & $16 \pm 4$ & 0.12 & 0.93 [0.84-1.03] & $0.95[0.85-1.05]$ & $0.97[0.838-1.08]$ \\
\hline Cort.SD.Stress Mpa & $4.4 \pm 1.4$ & $4 \pm 1.2$ & 0.08 & $0.79[0.60-1.04]$ & $0.83[0.63-1.10]$ & $0.90[0.68-1.21]$ \\
\hline Stiffness $\mathrm{kN} / \mathrm{mm}^{2}$ & $114 \pm 28$ & $120 \pm 27$ & 0.13 & $1.30[0.92-1.85]$ & $1.22[0.85-1.74]$ & $1.09[0.77-1.55]$ \\
\hline App.Modulus & $2740 \pm 720$ & $3032 \pm 732$ & 0.01 & 1.49 [1.07-2.05]* & $1.42[1.02-1.97]^{*}$ & $1.30[0.92-1.84]$ \\
\hline Est.Failure.Load N & $2736 \pm 634$ & $2882 \pm 638$ & 0.17 & $1.27[0.90-1.80]$ & $1.18[0.83-1.69]$ & $1.07[0.76-1.52]$ \\
\hline \multicolumn{7}{|l|}{$\underline{\text { Tibia }}$} \\
\hline Tt.vBMD mg/cm ${ }^{3}$ & $228 \pm 60$ & $239 \pm 47$ & 0.24 & $1.28[0.95-1.74]$ & $1.28[0.948-1.742]$ & $1.06[0.76-1.47]$ \\
\hline Ct.vBMD mg/cm ${ }^{3}$ & $757 \pm 97$ & $784 \pm 78$ & 0.08 & $1.34[1.02-1.76]^{*}$ & $1.31[0.99-1.72]$ & $1.14[0.84-1.55]$ \\
\hline Tb.vBMD mg/cm ${ }^{3}$ & $142 \pm 36$ & $148 \pm 34$ & 0.28 & $1.20[0.89-1.63]$ & $1.10[0.81-1.51]$ & $1.08[0.79-1.47]$ \\
\hline Ct.Th $\mu \mathrm{m}$ & $741 \pm 337$ & $792 \pm 258$ & 0.34 & $1.21[0.90-1.63]$ & $1.18[0.87-1.59]$ & $1.00[0.72-1.39]$ \\
\hline Ct.Po & $104 \pm 9$ & $103 \pm 11$ & 0.32 & $0.90[0.73-1.11]$ & 0.89 [0.72-1.09] & $0.90[0.71-1.15]$ \\
\hline Tb.N* mm-1 & $1.7 \pm 0.4$ & $1.7 \pm 0.4$ & 0.94 & $0.96[0.71-1.31]$ & $0.90[0.66-1.22]$ & $0.88[0.65-1.19]$ \\
\hline Tb.Th $\mu \mathrm{m}$ & $71 \pm 13$ & $74 \pm 13$ & 0.13 & $1.33[0.97-1.82]$ & $1.29[0.94-1.77]$ & $1.31[0.95-1.80]$ \\
\hline Tb.Sp $\mu \mathrm{m}$ & $548 \pm 168$ & $553 \pm 186$ & 0.85 & $1.04[0.74-1.45]$ & 1.14 [0.80-1.63] & $1.16[0.81-1.67]$ \\
\hline Tb.Sp SD $\mu \mathrm{m}$ & $290 \pm 156$ & $296 \pm 221$ & 0.82 & $1.02[0.73-1.44]$ & $1.12[0.78-1.60]$ & 1.15 [0.78-1.69] \\
\hline TrabDistLoad \% & $57 \pm 10$ & $56 \pm 10$ & 0.81 & $0.99[0.73-1.32]$ & $0.96[0.72-1.28]$ & $1.07[0.80-1.44]$ \\
\hline TrabProxLoad \% & $35 \pm 12$ & $34 \pm 10$ & 0.47 & $0.89[0.67-1.21]$ & 0.88 [0.66-1.18] & $0.99[0.74-1.33]$ \\
\hline TrabAvStress Mpa & $4 \pm 1.7$ & $3.9 \pm 1.3$ & 0.69 & $0.96[0.74-1.26]$ & $1.00[0.76-1.31]$ & $1.03[0.76-1.39]$ \\
\hline TTrabSDStress Mpa & $2.2 \pm 0.9$ & $2.1 \pm 0.8$ & 0.25 & $0.86[0.67-1.10]$ & 0.89 [0.69-1.15] & 0.91 [0.69-1.19] \\
\hline CortAvStress Mpa & $7.3 \pm 2.7$ & $7 \pm 2.4$ & 0.44 & $0.90[0.70-1.17]$ & $0.94[0.72-1.22]$ & $0.96[0.72-1.27]$ \\
\hline CortSDStress Mpa & $1.7 \pm 0.7$ & $1.6 \pm 0.6$ & 0.15 & $0.83[0.65-1.06]$ & $0.85[0.66-1.10]$ & $0.90[0.68-1.18]$ \\
\hline Tstiffness $\mathrm{kN} / \mathrm{mm}^{2}$ & $297 \pm 62$ & $304 \pm 55$ & 0.45 & $1.15[0.85-1.55]$ & $1.08[0.78-1.46]$ & $0.97[0.69-1.37]$ \\
\hline
\end{tabular}




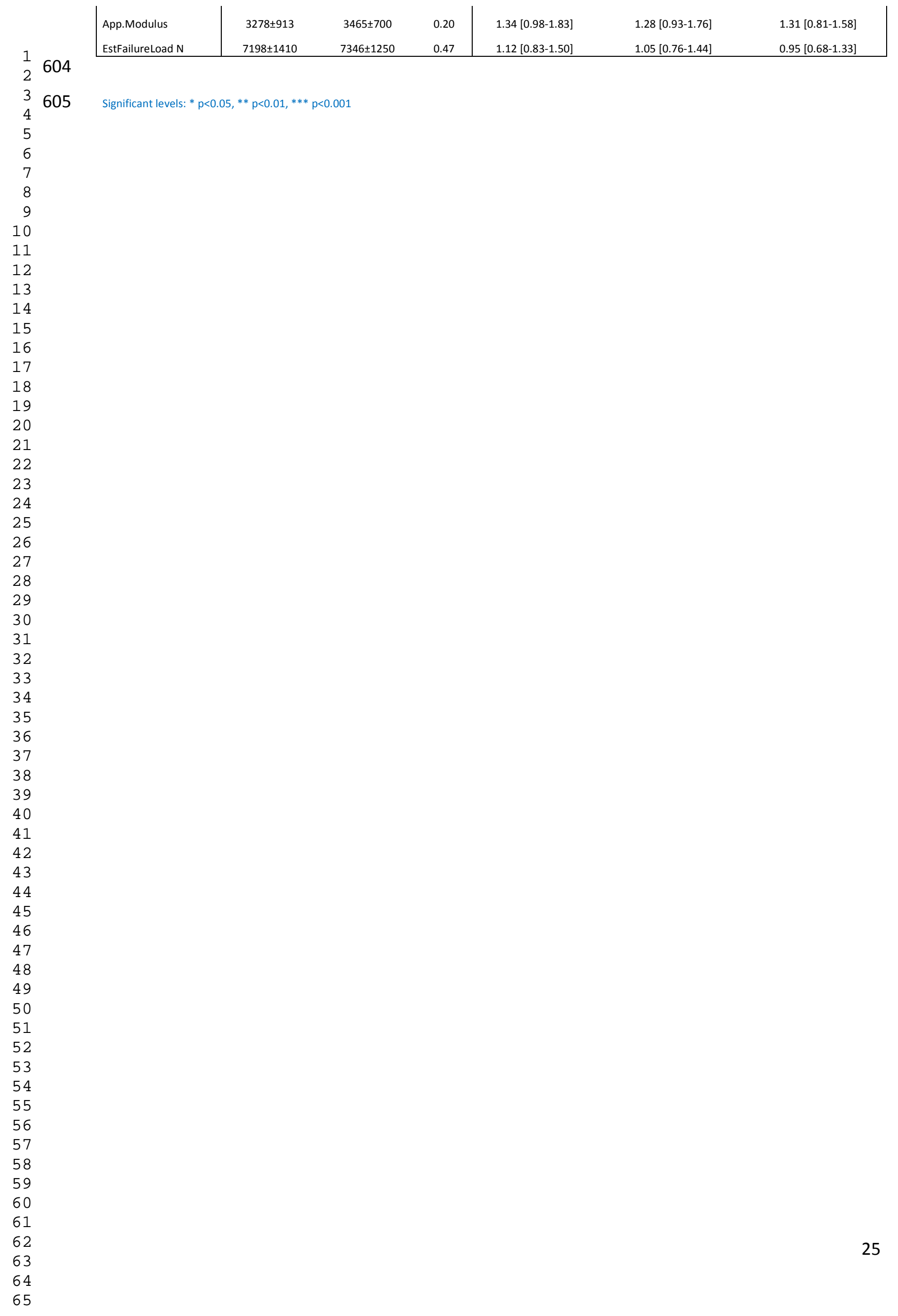


Table 4: PCA on nested case study (NC, left columns) and follow up (FU, right columns) at radius and tibia.

1

2

\begin{tabular}{|c|c|c|c|c|c|c|c|c|c|c|c|c|c|c|c|c|}
\hline \multirow{3}{*}{$\begin{array}{l}\text { Component of } \\
\text { variables }\end{array}$} & \multicolumn{8}{|c|}{ Radius } & \multicolumn{8}{|l|}{ Tibia } \\
\hline & PC 1 & & PC 2 & & PC 3 & & & $\mathrm{~F}$ & PC1 & & PC2 & & PC3 & & PC4 & \\
\hline & $\mathrm{NC}$ & $\mathrm{FU}$ & $\mathrm{NC}$ & $\mathrm{FU}$ & $\mathrm{NC}$ & $\mathrm{FU}$ & $\mathrm{NC}$ & u & NC & FU & NC & FU & NC & FU & NC & FU \\
\hline aBMD & 0.26 & 0.27 & $\begin{array}{c}- \\
0.06 \\
-\end{array}$ & $\begin{array}{c}- \\
0.03 \\
-\end{array}$ & 0.05 & 0.06 & $\begin{array}{c}- \\
0.11 \\
-\end{array}$ & - & 0.19 & 0.19 & 0.07 & 0.06 & 0.16 & 0.18 & 0.04 & 0.08 \\
\hline Tt.vBMD & 0.26 & 0.27 & $\begin{array}{c}0.12 \\
-\end{array}$ & $\begin{array}{c}0.10 \\
-\end{array}$ & 0.28 & 0.28 & 0.08 & - & 0.29 & 0.30 & 0.17 & 0.17 & 0.25 & 0.26 & $\begin{array}{c}0.00 \\
-\end{array}$ & $\begin{array}{c}0.06 \\
-\end{array}$ \\
\hline Ct.vBMD & 0.17 & 0.20 & 0.34 & 0.33 & 0.12 & 0.10 & 0.13 & - & 0.14 & 0.19 & $\begin{array}{c}0.35 \\
-\end{array}$ & $\begin{array}{c}0.33 \\
-\end{array}$ & 0.04 & 0.02 & 0.16 & 0.17 \\
\hline Tb.vBMD & 0.24 & 0.23 & $\begin{array}{c}0.25 \\
-\end{array}$ & $\begin{array}{c}0.27 \\
-\end{array}$ & 0.21 & 0.24 & 0.00 & - & 0.28 & 0.25 & 0.17 & 0.17 & 0.26 & 0.32 & $\begin{array}{c}0.12 \\
-\end{array}$ & $\begin{array}{c}0.21 \\
-\end{array}$ \\
\hline Ct.Th & 0.20 & $\begin{array}{c}0.23 \\
-\end{array}$ & 0.31 & 0.30 & $\begin{array}{c}0.12 \\
-\end{array}$ & $\begin{array}{c}0.11 \\
-\end{array}$ & $\begin{array}{c}0.00 \\
-\end{array}$ & - & $\begin{array}{c}0.17 \\
-\end{array}$ & $\begin{array}{c}0.22 \\
-\end{array}$ & $\begin{array}{c}0.38 \\
-\end{array}$ & $\begin{array}{c}0.36 \\
-\end{array}$ & $\begin{array}{c}0.11 \\
-\end{array}$ & $\begin{array}{c}0.07 \\
-\end{array}$ & $\begin{array}{c}0.11 \\
-\end{array}$ & $\begin{array}{c}0.10 \\
-\end{array}$ \\
\hline Ct.Po & -0.04 & 0.06 & 0.21 & 0.22 & 0.52 & 0.52 & $\begin{array}{c}0.11 \\
-\end{array}$ & - & 0.02 & 0.05 & $\begin{array}{c}0.21 \\
-\end{array}$ & 0.26 & 0.21 & 0.16 & $\begin{array}{c}0.04 \\
-\end{array}$ & $\begin{array}{c}0.08 \\
-\end{array}$ \\
\hline Tb.N & 0.19 & 0.18 & 0.27 & 0.30 & 0.00 & 0.02 & 0.37 & - & 0.18 & 0.17 & 0.24 & 0.24 & 0.20 & 0.32 & 0.35 & 0.28 \\
\hline Tb.Th & 0.17 & $\begin{array}{c}0.17 \\
-\end{array}$ & $\begin{array}{c}0.08 \\
-\end{array}$ & $\begin{array}{c}0.09 \\
-\end{array}$ & $\begin{array}{c}0.34 \\
-\end{array}$ & $\begin{array}{c}0.38 \\
-\end{array}$ & 0.44 & - & $\begin{array}{c}0.13 \\
-\end{array}$ & $\begin{array}{c}0.11 \\
-\end{array}$ & 0.07 & 0.08 & $\begin{array}{c}0.11 \\
-\end{array}$ & $\begin{array}{c}0.02 \\
-\end{array}$ & 0.59 & 0.62 \\
\hline Tb.Sp & -0.17 & $\begin{array}{c}0.17 \\
-\end{array}$ & $\begin{array}{c}0.27 \\
-\end{array}$ & $\begin{array}{c}0.31 \\
-\end{array}$ & $\begin{array}{c}0.01 \\
-\end{array}$ & $\begin{array}{c}0.03 \\
-\end{array}$ & 0.41 & - & $\begin{array}{c}0.20 \\
-\end{array}$ & $\begin{array}{c}0.19 \\
-\end{array}$ & 0.25 & 0.25 & $\begin{array}{c}0.20 \\
-\end{array}$ & $\begin{array}{c}0.33 \\
-\end{array}$ & 0.34 & 0.26 \\
\hline Tb.Sp SD & -0.17 & 0.16 & 0.25 & 0.28 & 0.01 & 0.04 & 0.43 & - & 0.19 & $\begin{array}{c}0.18 \\
-\end{array}$ & $\begin{array}{c}0.22 \\
-\end{array}$ & $\begin{array}{c}0.22 \\
-\end{array}$ & 0.17 & 0.29 & 0.34 & 0.27 \\
\hline Trab.Dist.Load & 0.07 & 0.05 & 0.40 & 0.41 & $\begin{array}{c}0.06 \\
-\end{array}$ & 0.11 & 0.23 & - & 0.05 & 0.01 & $\begin{array}{c}0.40 \\
-\end{array}$ & $\begin{array}{c}0.40 \\
-\end{array}$ & $\begin{array}{c}0.03 \\
-\end{array}$ & 0.08 & 0.27 & 0.31 \\
\hline Trab.Prox.Load & 0.07 & $\begin{array}{c}0.05 \\
-\end{array}$ & 0.40 & 0.42 & 0.02 & 0.02 & 0.24 & - & $\begin{array}{c}0.07 \\
-\end{array}$ & $\begin{array}{c}0.02 \\
-\end{array}$ & 0.39 & 0.40 & 0.04 & 0.01 & 0.26 & 0.28 \\
\hline Trab.Av.Stress & -0.18 & 0.20 & $\begin{array}{c}0.16 \\
-\end{array}$ & $\begin{array}{c}0.13 \\
-\end{array}$ & 0.42 & 0.44 & 0.17 & - & $\begin{array}{c}0.22 \\
-\end{array}$ & $\begin{array}{c}0.24 \\
-\end{array}$ & 0.05 & 0.14 & 0.40 & 0.34 & $\begin{array}{c}0.21 \\
-\end{array}$ & 0.25 \\
\hline Trab.SD.Stress & $\mid-0.29$ & $\begin{array}{c}0.29 \\
-\end{array}$ & $\begin{array}{c}0.01 \\
-\end{array}$ & $\begin{array}{c}0.04 \\
-\end{array}$ & 0.17 & 0.15 & $\begin{array}{c}0.08 \\
-\end{array}$ & - & $\begin{array}{c}0.28 \\
-\end{array}$ & $\begin{array}{c}0.29 \\
-\end{array}$ & 0.04 & 0.13 & 0.36 & 0.33 & $\begin{array}{c}0.04 \\
-\end{array}$ & 0.00 \\
\hline Cort.Av.Stress & $\mid-0.28$ & $\begin{array}{c}0.28 \\
-\end{array}$ & 0.02 & 0.02 & 0.21 & 0.20 & 0.08 & - & $\begin{array}{c}0.26 \\
-\end{array}$ & $\begin{array}{c}0.27 \\
-\end{array}$ & 0.06 & 0.15 & 0.38 & 0.34 & 0.02 & 0.02 \\
\hline Cort.SD.Stress & -0.27 & 0.28 & $\begin{array}{c}0.10 \\
-\end{array}$ & $\begin{array}{c}0.07 \\
-\end{array}$ & $\begin{array}{c}0.13 \\
-\end{array}$ & $\begin{array}{c}0.11 \\
-\end{array}$ & 0.07 & - & 0.27 & 0.30 & 0.08 & 0.02 & $\begin{array}{c}0.36 \\
-\end{array}$ & $\begin{array}{c}0.34 \\
-\end{array}$ & 0.02 & 0.06 \\
\hline Stiffness & 0.27 & 0.28 & $\begin{array}{c}0.06 \\
-\end{array}$ & $\begin{array}{c}0.10 \\
-\end{array}$ & 0.18 & 0.17 & 0.17 & - & 0.32 & $\begin{array}{c}0.34 \\
-\end{array}$ & 0.06 & 0.00 & 0.08 & 0.06 & 0.11 & 0.13 \\
\hline App.Modulus & 0.25 & 0.26 & 0.18 & 0.02 & $\begin{array}{c}0.22 \\
-\end{array}$ & $\begin{array}{c}0.23 \\
-\end{array}$ & 0.09 & - & 0.24 & 0.27 & 0.29 & $\begin{array}{c}0.28 \\
-\end{array}$ & 0.15 & $\begin{array}{c}0.11 \\
-\end{array}$ & 0.13 & 0.17 \\
\hline Failure Load & 0.27 & 0.28 & 0.03 & 0.00 & 0.20 & 0.19 & 0.17 & - & 0.32 & 0.34 & 0.04 & 0.02 & 0.07 & 0.07 & 0.07 & 0.09 \\
\hline \multirow[t]{3}{*}{$\begin{array}{l}\text { Percentage of } \\
\text { variance }\end{array}$} & 50.0 & 50.1 & 22.8 & 22.0 & 10.2 & 10.1 & 7.7 & - & 37.2 & 37.2 & 23.5 & 23.5 & 14.6 & 14.6 & 10.8 & 10.8 \\
\hline & & $\begin{array}{l}1.16 \\
{[1.0}\end{array}$ & $\begin{array}{l}0.97 \\
{[0.8}\end{array}$ & $\begin{array}{l}0.99 \\
{[0.8}\end{array}$ & $\begin{array}{l}1.22 \\
{[0.9}\end{array}$ & $\begin{array}{l}1.16 \\
{[0.7}\end{array}$ & $\begin{array}{l}1.04 \\
{[0.8}\end{array}$ & & $\begin{array}{l}1.10 \\
{[0.9}\end{array}$ & $\begin{array}{l}1.10 \\
{[0.9}\end{array}$ & $\begin{array}{l}1.10 \\
{[0.9}\end{array}$ & $\begin{array}{l}1.10 \\
{[0.9}\end{array}$ & $\begin{array}{l}1.01 \\
{[0.8}\end{array}$ & $\begin{array}{l}1.01 \\
{[0.8}\end{array}$ & $\begin{array}{l}1.02 \\
{[0.8}\end{array}$ & $\begin{array}{l}1.02 \\
{[0.8}\end{array}$ \\
\hline & 1.21 & 4- & $5-$ & 3- & 9- & 4- & $3-$ & & 9- & 9- & $8-$ & $8-$ & $8-$ & $8-$ & 6- & 6- \\
\hline $\mathrm{HR}$ & $\begin{array}{l}{[1.35]} \\
0.000\end{array}$ & $\begin{array}{c}1.20 \\
] \\
0.00\end{array}$ & ] & ] & ] & ] & ] & - & ] & ] & $\begin{array}{c}1.24 \\
]\end{array}$ & $\stackrel{1.24}{]}$ & {$\left[\begin{array}{c}1.17 \\
]\end{array}\right.$} & ] & $\begin{array}{l}1.21 \\
]\end{array}$ & ] \\
\hline$p$-value & 6 & 8 & 0.71 & 0.9 & 0.06 & 0.28 & 0.75 & - & 0.06 & 0.06 & 0.12 & 0.12 & 0.86 & 0.86 & 0.82 & 0.82 \\
\hline
\end{tabular}




\begin{tabular}{|c|c|c|c|c|c|c|c|c|}
\hline \multicolumn{2}{|c|}{ Fractures } & \multicolumn{4}{|c|}{ First part - before HR-pQCT } & \multicolumn{3}{|c|}{ Second part - after HR-pQCT } \\
\hline & & $\begin{array}{c}\text { Total } \\
\text { women }\end{array}$ & $\begin{array}{l}\text { Multiple } \\
\text { fractures }\end{array}$ & & $\begin{array}{c}\text { Reevaluated } \\
\text { women }\end{array}$ & $\begin{array}{c}\text { Total } \\
\text { women }\end{array}$ & $\begin{array}{c}\text { Initial } \\
\text { case } \\
\text { women }\end{array}$ & $\begin{array}{c}\text { Initial } \\
\text { control } \\
\text { women }\end{array}$ \\
\hline & Total & 188 & $37 / 20$ & 225 & 119 & 46 & 16 & 30 \\
\hline \multirow{4}{*}{ MOFs FRAX } & Hip & 17 & 2 & 19 & 8 & 6 & 3 & 3 \\
\hline & Shoulder & 29 & $5 / 3$ & 34 & 16 & 9 & 3 & 6 \\
\hline & Wrist & 53 & $5 / 5$ & 58 & 36 & 10 & 5 & 5 \\
\hline & Vertebrae & 28 & $8 / 3$ & 36 & 11 & 14 & 3 & 11 \\
\hline \multirow{7}{*}{$\begin{array}{l}\text { Other major } \\
\text { fractures }\end{array}$} & Pelvis & 7 & $4 / 2$ & 11 & 5 & 4 & 1 & 3 \\
\hline & Ankle & 19 & $5 / 3$ & 24 & 11 & 1 & 1 & 0 \\
\hline & Elbow & 3 & $1 / 1$ & 4 & 3 & 1 & 0 & 1 \\
\hline & Femur & 0 & 1 & 1 & 0 & 0 & 0 & 0 \\
\hline & Tibia & 1 & $2 / 1$ & 3 & 1 & 0 & 0 & 0 \\
\hline & Humerus & 1 & 0 & 1 & 1 & 0 & 0 & 0 \\
\hline & Sacrum & 3 & 0 & 3 & 2 & 0 & 0 & 0 \\
\hline \multirow{8}{*}{$\begin{array}{l}\text { Non major } \\
\text { fractures }\end{array}$} & Carpus & 3 & 0 & 3 & 3 & 0 & 0 & 0 \\
\hline & Clavicle & 1 & 0 & 1 & 1 & 0 & 0 & 0 \\
\hline & Ribs & 4 & 2 & 6 & 4 & 0 & 0 & 0 \\
\hline & Metatarsus & 12 & $2 / 2$ & 14 & 11 & 0 & 0 & 0 \\
\hline & Metacarpus & 0 & 0 & 0 & 0 & 1 & 0 & 1 \\
\hline & Patella & 2 & 0 & 2 & 2 & 0 & 0 & 0 \\
\hline & Scapula & 1 & 0 & 1 & 0 & 0 & 0 & 0 \\
\hline & Tarsus & 4 & 0 & 4 & 4 & 0 & 0 & 0 \\
\hline MOFs FRAX & $\%$ & 67.6 & 54.1 & 65.3 & 59.7 & 84.8 & 87.5 & 83.3 \\
\hline All major & $\%$ & 85.6 & 89.2 & 86.2 & 79.0 & 97.8 & 100 & 96.7 \\
\hline $\begin{array}{l}\text { Mean time } \\
\text { to first fracture }\end{array}$ & Days & $\begin{array}{l}956 \pm 591 \\
{[5-2269]}\end{array}$ & - & - & $\begin{array}{l}973 \pm 619 \\
{[5-2269]}\end{array}$ & $\begin{array}{c}803 \pm 419 \\
{[18-1594]}\end{array}$ & $\begin{array}{c}817 \pm 482 \\
{[18-1594]}\end{array}$ & $\begin{array}{c}795 \pm 391 \\
{[51-1438]}\end{array}$ \\
\hline
\end{tabular}


619 Highlights

1

622

623

- 417 women of the FRISBEE cohort, matched for FRAX, were evaluated by HR-pQCT

- Some HR-pQCT parameters, mainly at radius, are discriminating for prevalent fractures

- HR-pQCT improves the risk prediction beyond the DXA but not the FRAX score

- UDR aBMD also provides valuable information 
Click here to access/download RDM Data Profile XML BONE-D-20-00367_DataProfile.xml 
Authorship Statement

1. Conception or design of the work.

Cappelle S.I., Body J.J., Bergmann P, Moreau M.

2. Data collection.

Cappelle S.I, Kinnard V.

3. Data analysis and interpretation.

Cappelle S.I., Bergmann P., Moreau M., Body J.J.

4. Drafting the article.

Cappelle S.I., Bergmann P.

5. Critical revision of the article.

Chapurlat R, Blard P-H, Moreau M., Paesmans M., Rozenberg S., Rubinstein M., Surquin M., Karmali R., Baleanu F., Iconaru L.

6. Final approval of the version to be published.

Cappelle S.I., Moreau M., Karmali R., Iconaru L., Baleanu F., Kinnard V., Paesmans M., Rozenberg S., Rubinstein M., Surquin M., Blard P.-H., Chapurlat R., Body J.J., Bergmann P. 